\title{
STRATEGI BNNP SULSEL DALAM UPAYA PENANGGULANGAN PENYALAHGUNAAN OBAT PSIKOTROPIKA
}

\section{The Strategies Of BNNP South Sulawesi To Prevent The Misuse Of Psychotropic Drugs}

\author{
Paulus Duga Meman ${ }^{*}$, Rama Nur Kurniawan $K^{2}$, Lusyana Aripa ${ }^{3}$, Kartini ${ }^{4}$ \\ Fakultas Kesehatan Masyarakat Universitas Pancasakti Makassar
}

*Korespondensi: imercy758@gmail.com

\begin{abstract}
ABSTRAK
Psikotropika adalah zat/obat, baik alamiah maupun sintesis yang bermanfaat dibidang pengobatan, disisi lain sangat merugikan apabila dipergunakan tanpa pengawasan. Berdasarkan hasil observasi langsung di Kelurahan Maccini Sombala, sekitar 31 orang remaja yang sering menggonsumsi obat psikotropika. Dalam menanggulangi penyalahgunaan obat psikotropika, strategi yang diperlukan meliputi advokasi, dukungan social atau kemitraan dan pemberdayaan masyarakat (empowerment). Tujuan pelaksanaan strategi untuk memaksimalkan penerapan upaya promosi kesehatan dan pemberdayaan masyarakat, agar masyarakat mampu secara bersama-sama dalam menanggulangi penyalahgunaan psikotropika. Tujuan penelitian untuk mengetahui strategi BNNP SulSel dalam upaya penanggulangan penyalaguaan obat psikotropika di Kelurahan Maccini Sombala Kota Makasar. Penelitian ini menggunakan metode kualitatif dengan teknik wawancara mendalam. Jumlah informan sebanyak 5 orang, yang terdiri dari 3 laki-laki dan 2 perempuan. Strategi BNNP SulSel dalam penanggulangan penyalagunaan obat psikotropika dilakukan dengan komunikasi secara langsung dan tidak langsung. Advokasi dengan melakukan koordinasi di instansi pemerintah dan swasta. Dukungan sosialisasi dari masyarakat dengan mengikuti komunitas penggiat anti narkoba. Pemberdayaan masyarakat dilakukan dengan pemberian pelatihan dan keterampilan. Dapat disimpulkan bahwa upaya BNNP dalam menanggulangan penyalagunaan obat psikotropika dengan melakukan komunikasi langsung dan tidak tidak langsung, advokasi, dukungan sosial dan pemberdayaan, sehingga diharapkan kepada pihak BNNP Sul-Sel agar lebih banyak lagi membentuk kelompok penggiat anti narkoba dikalangan masyarakat
\end{abstract}

Kata kunci: Strategi promkes, BNNP Sulsel, Penaggulangan psikotropika

\section{ABSTRACT}

Psychotropic is one of the terms to referred those drugs that naturally and synthetically beneficial in medication yet could be dangerous when used without supervision. Based on the direct observation in Sub-district od Maccini Sombala, around 31 teenagers usually consume psychotropic drugs. To prevent the misuse of psychotropic drugs needs strategies that involve advocacy, social support, and community empowerment. Thus aims to maximalize the application of health promotion and community empowerment to prevent the misuse of psychotropic drugs. Objective This research aims to acknowledge the strategies of BNNP South Sulawesi to prevent the misuse of psychotropic drugs in the Sub-district of Maccini Sombala, Makassar City. Research conducted using a qualitative method with a data collection technique using an in-depth interview. There are five informants, consist of three men and two women. The result showed that direct and non-direct communication implemented the strategies of BNNP South Sulawesi to prevent the misuse of psychotropic drugs, as well as the advocacy were done by coordination in government and private agencies. Social support from the community is associated with the anti-narcotics community, and skill training for the empowerment of the community implemented by South Sulawesi's BNNP. It can be concluded that $B N N P$ 's efforts in dealing with the misuse of psychotropic drugs by conducting direct and indirect communication, advocacy, social support and empowerment, so that it is expected to the BNNP SulSel to form more anti-drug activist groups among the community.

Keywords: The strategies of BNNP South Sulawesi, prevention of psychotropic drugs misuse. 


\section{PENDAHULUAN}

Badan Narkotika Nasional (BNN) yang merupakan suatu lembaga pemerintah nonkementerian yang berkedudukan di bawah Presiden dan bertanggung jawab kepada Presiden, bertugas untuk melaksanakan tugas pemerintah di bidang pencegahan, pemberantasan penyalagunaan dan peredaran gelap psikotropika, precursor dan bahan adiktif lainnya kecuali bahan adiktif untuk tembakau dan alcohol. BNN berkedudukan di ibu kota negara dengan wilayah kerja meliputi seluruh wilayah Negara RI. BNN mempunyai perwakilan di daerah provinsi dan Kabupaten/Kota. BNN provinsi berkedudukan di ibukota provinsi dan BNN Kabupaten/Kota berkedudukan di ibu kota Kabupaten/Kota (Junaedi et al., 2019).

Penyalahgunaan NAPZA di dunia memiliki kenaikan hampir 12\% (15,5 juta jiwa sampai dengan 36,6 juta jiwa) dari pengguna pecandu berat. Menurut World Drug Report NAPZA meningkat salah satunya diperkiraan produksi opium meningkat dari 4.700 ton di tahun 2010 menjadi 7.000 ton di tahun 2011 dan menurut penelitian yang sama dari sisi jenis narkotika, ganja menduduki peringkat pertama yang disalahgunakan di tingkat global dengan angka pravalensi 2,3\% dan 2,9\% per tahun (Sholihah, 2015)

Secara statistik global, rata-rata 243 juta penduduk di dunia yang umur dari15-64 tahun telah menggunakan obat terlarangterutama ganja, opioid, kokain, dan amphetamine-tipe stimulan (ATS) dengan angka kematian diperkirakan mencapai 20 juta pertahun (WHO, 2010 dalam Nurjanisah et al., 2017)

Angka prevalensi penyalagunaan narkoba di Indonesia, didasari oleh 3 (tiga) hasil survei yaitu survei pada kelompok pelajar dan mahasiswa, kelompok pekerjaan dan kelompok rumah tangga.Penyalagunaan narkoba tida dapat di lakukan secara serentak kepada tiga kelompok sasaran tersebut karena keterbartasan utama minimnya anggaran. Pada tahun 2006, BNN bekerjasama denganpusat penelitian kesehatan UI melakukan survei terhadap penyalagunaan narkoba pada kelompok pelajar dan mahasiswa dan di peroleh angka prevalensi setahun terakhir pakai sebesar $1,9 \%$. Jika membandikan hasil survei tersebut, maka angka prevalensi bukan lagi sekedar dapat di tahan lajunya, namun dapat di turunkan dari 2,2\%di tahun 2015 menjadi $1,9 \%$ pada tahun 2016 , dengan penurunan laju angka prevalensia sebesar 0,3\%. Lalu peningkatan prevelensi penyalagunaan narkoba di peroleh dengn memandingkan tren angka prevensia penyalaguaan narkoba pada kelompok pelajar dan mahasiswa tentunya sangat mempengaruhi perkembangan angka prevalensi penyalagunaan narkoba secara umum (Pusat Data dan Infomasi Kementerian RI, 2017)

Provinsi Sulsel juga menjadi salah satu sasaran peredaran narkoba lintas provinsi, yakni melalui Pelabuhan Parepare, Bandara Internasional Soekarno Hatta, Bandara Internasional Sultan Hasanuddin, dan lintas 
http://journal.unpacti.ac.id/index.php/JPP

darat. Pada akhir tahun 2015 BNNP Sulsel merilis, dari 1.280 penyalahgunaan narkoba yang direhabilitasi, golongan usia 12-16 tahun sebanyak 5,72\%, golongan usia 17-41 tahun sebanyak $86,19 \%$ dan bahkan usia lanjut usia 42-57 tahun sebanyak 1,49\%. Dari data ini membuktikan bahwa bukan hanya usia remaja yang dikorbankan, tetapi usia anak- anak dan bahkan lanjut usia pun masih terjebak pada pusaran penyalahgunaan narkoba (Primawardan \& Kurniawanana, 2016)

Berdasarkan data yang di ambil langsung dari laporan tahunan 2019 bidang rehabilitas BNNP Sel-Sel (DWNP, 2019) mengatakan bahwa, Layanan rehabilitasi melalui BNN Wilayah Sulawesi Selatan tahun 2019 sebanyak 1.334 orang yang terdiri dari 453 orang (RI) dan 881 orang (RJ) yang terdistribusi berdasarkan jenis layanan pada Lembaga Institusi Pemerintah dan komponen masyarakat. Pada Lembaga instansi pemerintah tercatat total Rawat Inap yang ditargetkan sebanyak 300 orang terealisasi sebanyak 321 orang (107\%), kemudian Rawat Jalan (RJ) yang ditargetkan sebanyak 570 orang dan terealisasi sebanyak 636 orang (111,58\%). Pada Lembaga Rehabilitasi Komponen Masyarakat untuk jenis layanan Rawat Inap (RI) dari target 115 orang telah tereallisasi sebanyak 132 orang $(114,78 \%)$ dan untuk jenis layanan Rawat Jalan (RJ) dengan target 335 orang dan realisasi 245 orang $(73,13 \%)$. Berdasarkan pendampingan rawat lanjut setelah proses layanan pasca rehabilitasi rawat jalan maupun rumah damping sampai dengan bulan desember tahun 2019 dilakukan pada 179 klien, Berdasakan beberapa instrument alat tes dan hasil konseling didapatkan bahwa terdapat 125 orang (69\%) dikategorikan pulih produktif, 32 orang $(17,88 \%)$ pulih tidak produktif, 13 orang (26\%) tidak pulih produktif dan 9 orang $(5,03 \%)$ dikategorikan tidak pulih tidak produktif.

Pada tahun 2018 di kota Makassar pengedar dan penyalagunaan narkoba semakin banyak dan satuan reserse Narkoba polrestabes Makasar menangani 421 kasus narkoba, meningkat 5 kasus di banding tahun 2017. Kepala Reserse Narkoba Polrestabes Makasar, Kompol Diari Astetika mengungkapkan jaringan pelaku penyalagunaan narkoba di makasar kini lebih rapi hingga semakin susah dilacak (Himawan, 2018).

Berdasarkan hasil observasi langsung salah satu informen yang ada di Kelurahan Maccini Sombala, menyatakan bahwa banyak remaja yang menyalahgunakan obat psikotropika di usia 12-29 sekitar 31 orang remaja di Kelurahan Maccini Sombala yang sering menggonsumsi obat psikotropika, 13 orang diantaranya adalah remaja yang berdomisili di Kelurahan Maccini Sombala, serta 18 orang lainya adalah remaja yang berasal dari luar kelurahan tersebut, yang hanya datang saat ingin membeli atau menggonsumsi obat tersebut. Dan obat yang sering di gunakan adalah Tramadol, Trihexyphenidyl (THD) dan Somadril Jumlah kasus penyalahgunaan obat psikotorpika di 
http://journal.unpacti.ac.id/index.php/JPP

kalangan remaja di Kelurahan Maccini

Sombala.

\section{BAHAN DAN METODE}

Jenis penelitian yang di gunakan adalah penelitian kualitatif dengan design fenomenologi yang sifatnya mengeksplorasi secara mendalam informasi dari BNNP Sulsel mengenai strategi promosi kesehatan dalam penanggulangn penyalagunaan obat psikotropika. Penelitian ini dilaksanakan pada tanggal 5 Oktober 2020 di kantor BNNP Sulsel jalan Manunggal No 22, Maccini Sombala, Kecamatan Tamalate, Kota Makassar, Sulawesi Selatan. Penentuan subjek penelitian dengan menggunakan purposive sampling pegawai (BNNP) di Kelurahan Maccini Sombala yang bersedia di wawancarai. Teknik pengumpulan data dengan cara pengamatan langsung (observasi), dan wawancara mendalam. Pengecekan keabsahan data dengan cara triagulasi sumber, triagulasi waktu dan triagulasi teknik.

\section{HASIL}

Informan dalam penelitian ini adalah petugas BNNP Sul-Sel Maccini Sombala Kota Makassar. Krakteristik informan dalam penelitian ini meliputi insial, usia, jenis kelamin, jabatan, dan pendidikan. Informan yang berhasil diwawancarai oleh peneliti berjumlah 5 orang, yang terdiri dari petugas perencanaan program dan angaran (PPA), Kepala Seksi Pencegahan (KSP), Penyidik Badan narkotika nasional (BNNP) Kabit 2M dan Konselor. Rata-rata usia informan dalam penelitian 32-55 tahun, yang terdiri dari 3 informan berjenis kelamin laki-laki dan 2 informan berjenis kelamin perempuan.

\section{Advokasi}

Dari hasil wawancara yang dilakukan terhadap informan, tentang startegi BNNP Sul-Sel dalam upaya penanggulangan penyalagunaan obat psikotropika. Infroman menyatakan bahwa advokasi yang dilakukan yaitu melakukan koordinasi kepada orangorang yang berkepentingan (stakeholder) baik di instansi pemerintah seperti lembaga penegak hukum dan lembaga masyarakat maupun instansi swasta misalnya apotek (jual beli obat), seperti yang diungkapkan informan yaitu:

“..Melakukan koordinasi baik di instansi pemerintah maupun swasta seperti melakukan koordinasi step holder dek baik pemerintah daerah, lembaga penegak hukum, lembaga masyarakat swasta dan komponen masyarakat dalam upaya P4GN.."(AS, Oktober 2020)

\section{Dukungan Sosial}

Dari hasil wawancara yang dilakukan terhadap informan, tentangstartegi BNNP SulSel dalam upaya penanggulangan penyalagunaan obat psikotropika. Informan menyatakan bahwa bentuk dukungan sosial yang dilakukan yaitu masyarakat ikut serta dalam kelompok anti narkoba yang nantinya bisa berperan serta aktif dakam upaya pencegahan, pemberantasan, penyalagunaan dan peredaran gelap narkoba (P4GN), hal ini seperti yang diungkapkan oleh informan mengenai kelompok anti narkoba yaitu: 
“..masyarakat ikut serta dalam penggiat anti narkoba yang nantinya mereka biasa melakukn sosialisasi di keluarga dan masyarakat lain.." (AI, AS, SS IR, N, Agustus 2020)

\section{Pemberdayaan masyarakat}

Dari hasil wawancara yang dilakukan terhadap informan, tentangstartegi BNNP SulSel dalam upaya pemanggulangan penyalagunaan obat psikotropika. Infroman menyatakan bahwa pemberdayaan masyarakat yang dilakukan yaitu BNNP Sul-Sel memberikan pelatihan sablon baju kepada masyarakat terkhusus pecandu narkoba untuk bisa merubah pola pikir pebisnis kaos agar mereka bisamelupakan masa lalu mereka yang pernah dialami tidak terulang lagi, hal ini seperti yang diungkapkan oleh informan yaitu “..Memberikan pelatihan terhadap masyarakat seperti melati mereka dalam menghasilkan uang seperti sablon baju.." (AI, AS, SS, IR, N, Agustus 2020)

Selain memberikan pelatihan sablon baju informan juga mengatakan strategi pemberdayaan masyarakat yang dilakukan oleh BNNP Sul-Sel dalam upaya penanggulangan penyalagunaan obat psikotropika dengan memberikan pelatihan menjahit kepada masyarakat sehingga mereka mampu mencukupi kebutuhan ekonomi mereka dan tidak lagi tergiur memakai narkoba lagi, seperti yang diungkapkan informan berikut yaitu :

“..memberikan pelatihan kepada masyarakat seperti menjahit pakian agar mereka tidak terpengaru dengan mengkonsumsi narkoba.." (AI, AS, SS, IR, N Oktober 2020)

$$
\text { Selain melakukan pemberdayaan }
$$
masyarakat melalui pelatihan sablon baju dan pelatihan menjahit informan juga mengatakan strategi pemberdayaan masyarakat yang dilakukan oleh BNNP Sul-Sel dalam upaya penanggulangan penyalagunaan obat psikotropika yaitu dengan melakukan pelatihan servis hp sehingga suatu saat mereka bisa membuka layanan sevis hp dan tidak akan terpengaruh untuk mengkonsumsi narkoba,hal ini seperti yang diungkapkan informan berikut ini yaitu

“..BNNP sulsel memberikan keterampilan terhadap masyarakat yaitu memberikan keterampilan servis $H P . . "$ (AI, AS, SS, IR, N Oktober 2020)

\section{PEMBAHASAN}

Dari hasil wawancara mendalam yang diperoleh dari informan, maka dibuatlah suatu pembahasan dari setiap variabel yang diteliti, sebagai berikut:

\section{Strategi Advokasi}

Advokasi merupakan suatu upaya atau proses yang strategis dan terencana untuk mendapatkan komitmen dan dukungan dari pihak-pihak yang terkait (stake-holders). Pihak-pihak yang terkait ini berupa tokohtokoh masyarakat (formal dan informal) yang umumnya berperan sebagai narasumber (opinion leader), atau penentu kebijakan (norma) atau penyandang dana. Juga berupa kelompok-kelompok dalam masyarakat dan media massa yang dapat berperan dalam menciptakan suasana kondusif (Kemenkes RI, 2011). 
Dari hasil wawancara yang dilakukan peneliti terhadap informan bahwa advokasi yang dilakukan yaitu melakukan koordinasi baik di instansi pemerintah (Kelurahan Macini Sombala Kecamatan Tamalate Kota Makassar) maupun swasta, kusus Kelurahan Macini Sombala sebagai pailot projek untuk kelurahan bersih narkoba (bersinar)

Hasil penelitian ini sejalan dengan hasil penelitian (Namira et al., 2020) melakukan advokasi yaitu melakukan rapat koordinasi oleh lintas terkait, memberikan layanan program rehabilitasi, melakukan mediasi, kolaborasi, penyebaran leaflet dan selebaran, melakukan pemantauan dan pengawasan dalam layanan rehabilitasi dan paskarehabilitasi pada warga binaan, prosesnya berjalan dengan baik dalam pelaksanaan program rehabilitasi.

Dari hasil penelitian (Perwira, 2019) Salah satu bentuk usaha yang dilakukan oleh BNN adalah dengan melakukan kerjasama internasional dengan penegak hukum dari berbagai negara, dengan tujuan untuk menekan jumlah masuknya narkotika dari luar negeri yang akan dipasarkan di wilayah Negara Indonesia. Salah satu negara asal masuknya narkoba yang berhasil diungkapkan oleh BNN di Indonesia adalah Tiongkok meskipun, Tiongkok bukan merupakan negara dengan jumlah ungkapan kasus terbesar dalam data yang tercatat di BNN, Tiongkok mendapat perhatian khusus karena jumlah kuantitas barang bukti yang berhasil di ungkap merupakan jumlah terbanyak dibandingkan

Nigeria dan Iran

Berdasarkan hasil penelitian

(Triwibowo \& Nasional, 2020) dalam melaksanakan kegiatan advokasi BNNK Samarinda telah melaksanakan kegiatan seperti koordinasi dalam pembentukan wawasan anti narkoba (bang wawan) disekolah-sekolah, adapun hasil capaian dari kegiatan tersebut diantaranya beberapa sekolah bersedia lingkunganya untuk diisi kegiatan P4GN dengan melakukan penyuluhan secara mandiri kepada setiap siswanya secara rutin kemudian terbentuknya relawan di sekolah yang mana tujuanya juga sebagai perpanjangan tangan BNN dalam menyebarkan pesan-pesan P4GN dilingkungan sekolahnya.

Berdasarkan hasil penelitan yan di lakuakan oleh (Nurlaelah et al., 2019) adalah adanya upaya terpadu BNN dalam pemberantasan narkotika dilakukan dengan cara membangun dan meningkatkan pengetahuan, pemahaman dan kesadaran masyarakat tentang bahaya narkoba melalui kerjasama dengan aliansi pemerintah, non pemerintah dan juga masyarakat dalam upaya meningkatkan peran aktifnya dalam menciptakan lingkungan yang bebas dari masalah penyalagunaan dan peredaran narkotika.

\section{Strategi Dukungan Sosial}

Dukungan social menurut WHO merupakan suatu kerja sama formal antara individu-individu, kelomok-kelompok atau 
http://journal.unpacti.ac.id/index.php/JPP

organisasi-organisasi untuk mencapai suatu tugas atau tujuan tertentu.

\section{Berdasarkan hasil wawancara} mendalam pengetahuan informan tentang dukungan sosial untuk upaya penanggulangan penyalagunaan obat psikotropika yaitu mayarakat ikut serta dalam, penggiat atau aktifis-aktifis anti narkoba di kalangan masyarakat yang dibekali dengan pengetahuan tentang narkoba dan diharapkan mereka bisa melakukan sosialisasi di keluarganya sendiri dan masyarakat lainnya.

Berdasarkan hasil penelitian (Yusuf et al.,2010) bahwa pemberian dukungan masyarakat terhadap program yang dikeluarkan puskesmas mendapat dukungan sosial (social support) dari masyarakat itu sendiri. Proses dukungan ini terjadi karena pengetahuan mereka tentang kesehatan itu sudah mulai ada. Artinya bahwa setiap program yang ada telah merasa penting untuk kesehatan masyarakat. Proses perubahan perilaku untuk menerima program yang ada, terlihat ketika antusias masyarakat untuk berbondong-bondong ke puskesmas pembantu untuk meminta pelayanan kesehatan.

Berdasarkan hasil penelitian (Triwibowo \& Nasional, 2020) dalam upaya pencegahan dengan memberdayakan masyarakat yang dilakukan BNNK Samarinda yaitu membentuk satgas anti narkoba sebagai perpanjangan tangan BNN yang diharpakan mampu mempelopori dan berperan aktif dalam upaya P4GN dilingkungannya masingmasing dengan tujuan mewujudkan lingkungan kerja bersih narkoba dan kelurahan bersih narkoba. Dalam menjalankan tugasnya para satgas dan relawan yang terbentuk akan dibimbing dan dipantau oleh BNN agar menjadi andal, efektif dan mampu merekrut pemuda lainnya di daerahnya hingga ke tingkat kecamatan untuk diberikan pemahaman, penyadaran tentang bahaya obatobatan terlarang dengan memanfaatkan media sosial, di organisasi, sekolah dan di lingkungan sehari-harinya.

Berdasarkan hasil penelitian (Kurniawan., 2018) pemberdayaaan yang dilakukan oleh dinas kesehatan terhadap upaya penanggulangan narkoba dengan cara membentuk kader kesehatan remaja di sekolah dengan tujuan memberikan pemahaman terhadap siswa tentang bahaya penyalahgunaan napza bagi kesehatan, sehingga sehingga siswa memiliki kesadaran untuk ikut terlibat memerangi tindak penyalahgunaan narkoba. Hal ini senada dengan peneliti sebelumnya yang menjelaskan bahwa pemberdayaan masyarakat bidang kesehatan adalah upaya atau proses untuk menumbuhkan kesadaran kemauan dan kemampuan dalam memelihara dan meningkatkan kesehatan

Berdasarkan hasil penelitian yang dialkuakn oleh (Destriliaa et al) adalah pembentukan Satuan Tugas (satgas) Anti Narkoba (BINLO) untuk mengurangi tindak kejahatan. Satgas narkoba adalah salah satu bentuk startegi Kepolisian dalam menanganai pemberantasan kasus-kasus narkoba dimana 
setiap anggota Kepolisian bagian narkoba mempunyai tugas pokok dan fungsi yang berbeda-beda dalam menangani kasus-kasus penyalagunaan narkoba dan satgas narkoba atau bisa disebut BINLO adalah satuan kelompok anti narkoba yang diberi tugas dalam pemberantasan setiap macam-macam kasus narkoba yang ada di Kota Metro.

\section{Strategi Pemberdayaan Masyarakat}

Pemberdayaan masyarakat merupakan salah satu pendekatan atau strategi dimana masyarakat diberikan kuasa dan kekuatan melalui peningkatan pengetahuan dan ketrampilan supaya mereka mampu mengidentifikasi dan memprioritaskan kebutuhan mereka dan kemudian dapat mencari sumber daya untuk mengatasi permasalahan yang dihadapi(Triwibowo \& Nasional, 2020)

Berdasarkan hasil wawancara mendalam pengetahuan informan tentang pemberdayaan masyarakat yang dilakukan oleh petugas BNNP yaitu BNNP memberikan keterampilan terhadap masyarakat seperti keterampilan menjahit, sablon dan servis $\mathrm{hp}$

Hal ini sejalan dengan hasil penelitian yang dilakukan oleh (Nadra, 2017) menyatakan memiliki individu yang terampil mengenai kesehatan, akan berdampak positif terhadap kesehatan masyarakat apabila diaplikasikan. Karena individu merupakan bagian dari masyarakat, dan semakin banyak individu yang mengaplikasikan, kesehatan masyarakat akan semakin meningkat. Mengembangkan keterampilan dapat dilakukan dengan cara memberikan edukasi tentang cara memelihara kesehatan, mencegah penyakit, mendeteksi dini, dan materi kesehatan lain yang dapat diaplikasikan. Tujuan dari sarana ini adalah agar masyarakat dapat memahami dan melakukan apa yang telah dipelajari.

Berdasarkan data laporan tahun 2019 (DWNP, 2019) selama klien berada di Rumah Damping Celebes BNNP Sulsel, mereka juga diajarkan atau dilatih untuk membuat keterampilan (Vokasional) agar setelah mereka selesai menjalankan program Rumah Damping ini, mereka mempunyai bekal untuk kehidupan setelah selesai program dari Rumah Damping serta membuka peluang bagi klien untuk bisa hidup lebih produktif lagi. Adapun pelatihan vokasional yang diberikan selama Program Rumah Damping Celebes BNNP Sulsel selama semester I di tahun 2019.

Menurut (Fuadah, 2019) dalam Widjaja pemberdayaan adalah upaya untuk meningkatkan kemampuan dan potensi yang dimiliki oleh masyarakat, sehingga masyarakat dapat mewujudkan jati diri, harkat dan martabatnya secara maksimal untuk bertahan dan mengembangkan diri secara mandiri dibidang ekonomi, sosial, agama dan budaya. Pemberdayaan tidak cukup hanya dengan upaya meningkatkan produktivitas, memberikan kesempatan

\section{KESIMPULAN DAN SARAN}

Strategi Advokasi BNNP Sulsel dalam pencegahan penyalahgunaan psikotropika 
http://journal.unpacti.ac.id/index.php/JPP

dilakukan dengan membangun koordinasi

baik di instansi pemerintah maupun swasta.

Strategi dukungan social dengan keikutsertaan dari masyarakat dalam aktifis anti narkoba. Strategi pemberdayaan masyarakat dengan memberikan keterampilan menjahit, sablon dan servis hp kepada masyarakat.

Diharapkan kepada pihak BNNP SulSel agar tidak pernah berhenti untuk menyampaikan informasi baik secara lagsung ataupun secara tidak langsung terkait bahaya narkoba kepada kalangan manapun, hendaknya terus melakukan koordinasi baik di instansi pemerintah ataupun swasta dalam upaya penanggulangan penyalagunan narkoba, lebih banyak lagi membentuk kelompokkelompok/penggiat anti narkoba di kalangan masyarakat, serta memberikan pelathanpelatihan itu leibh bervariasi sesuai jaman kepada masyarakat agar mereka tidak bosan, supaya mereka tidak tergiur dengan mengkonsumsi narkoba, karna melihat kasus narkoba semakin hari semakin meningkat.

\section{DAFTAR PUSTAKA}

Destriliaa, I., Atika, D. B., \&Prihantika, I. (1858). Strategi Penanganan Narkoba Di Polres Metro (Studi Ifas Dan Efas).

Dewi, I. K. (2019). Pembinaan Dan Pendampingan Remaja Kick Boxing Guna Mencegah Prilaku Penyalahgunaan Narkoba. Jurnal Pengabdian Kepada Masyarakat Membangun Negeri, 2(1).Https://Doi.Org/10.35326/Pkm.V2i1. 201

Dwi, D., Siahaan, D., Hardjanto, U. S., \&Soemarmi, A. (2016). Pembentukan
Badan Narkotika Nasional Provinsi Jawa Tengah Dalam Penanggulangan Masalah Narkotika. 5.

DWNP. (2019). Laporan Tahunan Bidang Rehabilitasi Bnn Provinsi Sulawesi Selatan Badan.

Fuadah, S. (2019). Strategi Pemberdayaan Masyarakat Badan Narkotika Nasional Kota Cilegon Dalam Pencegahan Penyalahgunaan Narkotika Di Kalangan Remaja Usia Sekolah. Universitas Sultan Ageng Tirtayasa.

Himawan. (2018). Selama 2018, Kasus Narkoba Di Makassar Alami Peningkatan.

Ismiati. (2018). Strategi Badan Narkotika Nasional Kabupaten (Bnnk) Aceh Selatan Dalam Upaya Pencegahan Dan Penanganan Narkoba. Jurnal Al-Bayan, 24(2), 204-

Jumaidah, \&Rindu. (2017). Perilaku Pencegahan Penyalahgunaan Narkoba Pada Remaja Di Wilayah Kecamatan Sukmajaya, Depok. Jurnal Ilmiah Kesehatan,16.Http://Journals.Stikim.Ac.Id /Index.Php/Jikes/Article/View/286/213

Junaedi, Harakan, A., \&Idris, E. I. P. (2019). Kerjasama Bnn Dan Kepolisian Dalam Penanggulangan Penyalahgunaan Narkoba Di Kecamatan Rappocini Kota Makassar. 5.

Kemenkes RI. (2011). Promosi Kesehatan Di Daerah Bermasalah Kesehatan.

Kurniawan., R. N. (2018). Strategi Promosi Kesehatan Terhadap Upaya Penanggulangan Penyalahgunaan Narkoba. The Indonesian Journal Of Health Promotion, 1(1). Https://Doi.Org/10.1119/1.2218359

Murtiwidayanti, S. Y. (2018). Sikap Dan Kepedulian Remaja Dalam Penanggulangan Penyalahgunaan Narkoba. 17. 
Nadra, K. (2017). Situasi Strategi Promosi Kesehatan Di Vico Indonesia, Tahun 2016 Vico Indonesia Health Promotion Strategy Situation In 2016. Jurnal Promkes, 5(1), 93-104.

Namira, Ramli, \&Rahayu, A. (2020). Strategi Promosi Kesehatan Dalam Upaya Rehabilitasi Penyalahgunaan Narkoba Oleh Badan Narkotika Nasional Provinsi (BNNP) Maluku Utara Tahun 2019. Biosainstek., 2(1).

Nurlaelah, Harakan, A., \&Mone, A. (2019). Strategi Badan Narkotika Nasional (BNN) Dalam Mencegah Peredaran Narkotika Di Kota Makassar. Of Government And Political Studiens, 2.

Olivia, C. H. (2013). Strategi Komunikasi Badan Narkotika Nasional (BNN) Dalam Mengurangi Jumlah Pengguna Narkoba Di Kota Samarinda. 1(1), 428-441.

Perwira, A. Y. (2019). Kerjasama Bnn (Badan Narkotika Nasional) Indonesia Dan Nncc (National Narcotics Control Commissions) Tiongkok Dalam Menanggulangi Perdagangan Narkotika Asal Tiongkok Di Indonesia Tahun 2012 - 2018 Aldebaran. Journal Of Internasional Relations, 5. Https://Doi.Org/10.1017/Cbo9781107415 324.004
Primawardan, Y., \& Kurniawanana, A. R. (2016). Pendekatan Humanis Dalam Penanganan Anak Pelaku Tindak Pidana Penyalahgunaan Narkoba Studi Kasus Di Provinsi Sulawesi Selatan. Penelitian Hukum De Jure, 17.Pusat Data Dan Infomasi Kementerian Ri. (2017).

Randa, R. B. (2019). Strategi Komunikasi Badan Narkotika Nasional Provinsi Sulawesi Selatan Dalam Menyosialisasikan Dampak Narkoba Terhadap Pelajar Di Kota Makassar. Ilmu Komunikasi, 8.

Sholihah, Q. (2015). Efektivitas Program P4gn Terhadap Pencegahan Penyalahgunaan Napza. Jurnal Kesehatan Masyarakat. Https://Doi.Org/10.15294/Kemas.V10i2.3 376

Triwibowo, M. H., \&Nasional, B. N. (2020). Strategi Badan Narkotika Nasional Dalam Narkoba Di Kota Samarinda. Journal Ilmu Pemerintahan, 8(1), 233246.

Yusuf, Y., Syafar, M., \&Bahar, B. (2010). Analisis Strategi Promosi Kesehatan Di Puskesmas Bambalamotu Dalam Pembinaan Masyarakat Suku Da 'A. 6(3). 